\title{
The multiple perspectives in a dialogical continued education course on animal welfare: Accounts of a team of extension agents and a manager and a cowboy from a rural Brazilian territory
}

\author{
Luis Fernando S. Zuin ${ }^{\mathrm{a}, *}$, Poliana Bruno Zuin ${ }^{\mathrm{b}}$, Ana Gabriela Monzon ${ }^{\mathrm{c}, 1}$, \\ Mateus J.R. Paranhos da Costa ${ }^{\mathrm{d}}$, Isadora Rustino Oliveira ${ }^{\mathrm{a}}$ \\ ${ }^{a}$ Faculty of Animal Science and Food Engineering, University of Sao Paulo, Avenida Duque de Caxias Norte, 225, CEP 13635-900 \\ Pirassununga, São Paulo, Brazil \\ b Faculty of Technology, Science and Education, Avenida Painguás, 225, Jardim Urupês, CEP13630-250 Pirassununga, São Paulo, Brazil \\ c University of Sao Paulo, Avenida Duque de Caxias Norte, 225, CEP 13635-900 Pirassununga, São Paulo, Brazil \\ ${ }^{\mathrm{d}}$ Faculty of Agrarian Sciences and Veterinary, Department of Animal Science, State University of Sao Paulo Júlio de Mesquita Filho \\ (UNESP), Via de Acesso Dr. Paulo Donato Castellane km 5 Rural, CEP14884-900 Jaboticabal, Sao Paulo, Brazil
}

\section{A R T I C L E I N F O}

\section{Article history:}

Available online 18 September 2014

Keywords:

Rural extension

Brazil

Dialogism

Animal welfare

Rational management

Teaching-learning processes

\begin{abstract}
A B S T R A C T
The objective of this article is to describe and analyze practices of a training course in animal welfare with a strong dialogical component, as offered by state rural extension agents to a manager and cowboy of a rural Brazilian cattle ranch. This case study is part of a bigger research project financed by Brazil's National Council for Scientific and Technological Development $(\mathrm{CNPq})$ on dialogical communication, or dialogism, as an alternative approach to the predominant diffusion of innovations theory employed in teaching-learning processes in rural extension worldwide. This case study seeks to demonstrate that the dialogical course of rational management practices and animal welfare contributes significantly in the joint development of a more sustainable livestock production that is both less violent towards animals and addresses social constraints between the subjects involved in livestock production. Thus, dialogism significantly improves existing communication barriers inherent in society and the overall quality of life of the cowboys in their workplace.
\end{abstract}

(c) 2014 Elsevier Inc. All rights reserved.

\section{Introduction}

Every passing day Brazilian consumers demand more and more foods that come from an environmentally correct and a socially just production (Bonamigo, Bonamigo, \& Molento, 2012; Hernandes, Rubin, Dill, Oliveira, \& Silva, 2010; Machado, Paulillo, \& Lambert, 2008). Meat consumers are increasingly demanding to know the socio-economic and environmental history of the food they consume. This increasing consumer interest exerts market pressures for an improved management

\footnotetext{
* Corresponding author. Tel.: +55 1935654092.

E-mail addresses: Ifzuin@usp.br, Ifzuin@hotmail.com (L.F.S. Zuin), polianazuin@hotmail.com (P.B.Zuin), anagmonzon@fulbrightmail.org (A.G. Monzon), mpcosta@fcav.unesp.br (M.J.R. Paranhos da Costa), isadora.rustino.oliveira@usp.br (I.R. Oliveira).

1 Present address: 603 Southwest Parkway, Apartment 132, College Station, TX 77849, USA.
} 
of livestock in ranches. Realizing the need to seek the demanded sustainability in their productive systems, some cattle ranch owners strive to employ practices of animal welfare and rational management in their rural properties.

In the last two decades a significant increase in ranches adopting productive precepts that meet sustainable social and environmental dimensions in the productive context of raising Brazilian cattle is more and more apparent. Offering continued education courses in welfare management to men in the field handling the cattle is one of the different practices employed in Brazilian rural territories. According to Temple Grandin (1994), despite the fact that the latest technology and the best facilities are widely available to make cattle handling easier, all subjects responsible for the ranch need to be convinced that proper handling practices pay off economically. However, even when benefits are obvious for some people, stakeholders are willing to purchase new equipment than to invest in learning and practicing better welfare management methods (Grandin, 2003).

In fact, as reported by a trainer in this study, at times ranch stakeholders justify their disbelief for new management practices. For example, the manager under study claimed that "the cowboys are immutable subjects" and they are mostly concerned with their "living and working conditions, so they only need to be oriented on basic ways of work." This presents an incomplete assessment of the needs of the cowboy in the workplace, as the cowboy interviewed reported that he would like to grow professionally and learn beyond the fundamentals of animal management. More importantly, the discrepancy in the stated needs of the stakeholders involved in cattle production raises a bigger social issue common in Brazilian rural territories; communication barriers between well-educated ranch managers, owners and extension agents and the lesser educated cowboys create vertical and hierarchical relationships hindering the creation of sustainable productive systems.

Due to the inherent social differences between all ranch stakeholders and their respective point of views and perceptions of the world, professional development trainings must employ an approach capable of developing horizontal communication. Dialogical communication, or dialogism, is a horizontal approach in rural extension trainings that can introduce more equality between the subjects involved and result in the joint development of better practices in a given productive context. By using the theoretical framework provided by language philosopher Mikhail Bakhtin, we demonstrate that dialogical relationships between the subjects go beyond just the dialogues shared between subjects in the concrete world. Dialogue assumes a broader communicative sphere; within the dialogical context, I am constituted by and I constitute myself in my numerous relationships with others.

When extension agents or trainers use dialogism in their courses they must identify the verbal (dialogues) and non-verbal contexts that make up the reality of the subjects within their rural territories. One of the differentials of the training courses with a dialogical bias is the equipotency of voices generated by all course participants. Dialogical training courses specifically presuppose equipotent voices between the trainers and the ranch stakeholders. These multiple voices, in a horizontal didactic context, will produce a highly polyphonic training course (Bakhtin, 2012). Polyphony promotes significant dialogue among the course participants, confirming the various points of views and value judgments present in their enunciations (Ducrot, 1987). Equipotency and polyphony are necessary enablers of a joint construction of sustainable productive environments in rural areas.

The objective of this article is to describe and analyze the dialogical training practices of a course in animal welfare offered to a manager and cowboy in a Brazilian cattle ranch. We aim to study the dialogical communication approach embraced in this welfare management continued education course as an alternative model to diffusionism, the rural extension approach predominantly employed in Brazilian rural territories. At its core, the diffusionist model presents some assumptions that are diametrically opposed to dialogism (Freire, 2006). The diffusionist theory works with the dissemination of one-size technological packages in rural properties and the relationships between the trainers and the people that work in the rural properties tends to be vertical and hierarchical in nature. The opposite is true for dialogism, which brings about the sustainable joint development of new technologies and practices in the productive environment of rural areas (Zuin \& Zuin, 2008).

\section{Materials and methods}

The research for the case study hereby presented is financially supported by Brazil's National Council for Scientific and Technological Development (CNPq-Brazil). The case study employs a social-historical bias in which the research team collected information through interviews with the two subjects from a Brazilian rural ranch who participated in the continued education rational management course and the team of trainers offering the course. A voice recorder and a camera were utilized for data collection. The information collected during these interviews was analyzed mainly from the enunciations of the five subjects interviewed. For Freitas (2012), qualitative research with a dialogic approach possesses five assumptions:

- The source of the data collection is the context of the dialogues and situations, as it is in the interconnections between the subjects where the occurrences arise;

- It is not during the stage of developing of research questions that the collection and operationalization of variables are sought, instead during the interviews the researchers make an effort to fully comprehend the phenomena historically evidenced by the subjects;

- The process of data collection is characterized by generating senses and meanings of both the interviewers and the subjects being interviewed during the interviews and observations of the phenomena; 
- The investigator, or interviewer, is one of the two principal instruments of research because together with the subject being interviewed they will construct a space permeated by the two unique subjectivities, that of the interviewer and the interviewed;

- The criteria used for the research involve the unfolding and deep senses that surface from the enunciations of the subjects, of the inter-subjectivity that rises from their interpretation of the phenomena. The interviewer and the subject being interviewed possess an active posture that can be evidenced in the dialogues either as a disagreement or as consensus. From the resulting dialogue the subjects reflect, learn and give new meanings to their knowledge; thus, they generate and approximate their senses and meanings to the phenomenon researched about.

Five subjects were interviewed for this research, they include the team of three trainers in animal welfare management practices; the sole manager of the ranch that breeds and sells reproductive animals, and; one of five cowboys that works in the same ranch as the manager interviewed. One criterion for participating in the interviews was that the study participants must have received the course with the trainers chosen for analysis. The cowboy chosen had worked a long time in the ranch under study and had previously completed two courses of animal welfare with the chosen team of trainers. The considerations and assessments of this specific cowboy are relevant because not only are they based on his experience historically constituted in the ranch, but also because they are based on his shared lived experiences with cowboys from other ranches who also completed courses in animal welfare with him.

The following background information on the subjects' schooling and experience is important to highlight:

- Schooling: It was observed that all trainers interviewed have attained graduate degrees in Animal Science; two have doctorate degrees and one has a Master's degree. The ranch manager has an undergraduate degree in Veterinary Medicine and the cowboy completed elementary school.

- Trainers' experience in offering courses: The team has offered courses on animal welfare to managers and owners of Brazilian beef cattle ranches, cowboys and other ranch employees for ten years. Specifically, the leader of the trainers' team has a family background on beef cattle production and he worked as a beef farm manager for more than 4 years before he began delivering trainings on cattle welfare. Under his leadership, all trainers are trained to master most of the beef cattle handling procedures on their own.

- Experience of the manager and cowboy: The manager has worked in the rural property for three years with previous experience in other ranches. The first contact he had with the practices of rational management began when he was hired in the present ranch. The cowboy has worked in the ranch under study for 20 years. He stated during his interview that the practices of animal welfare were adopted by the owners of the ranch around 15 years ago.

The ranch chosen for study is a well-referenced property in Brazil. It is well-known for its existent practices on animal welfare and the use of rational management in the ranch's productive routines for more than 15 years. The motivation in adopting best management practices in the ranch began with the adoption of a program of cattle genetic improvement. The program selected animals that had better temperament and were more docile because, according to the ranch owner, these animals are more productive and are overall easier to manage. Grandin and Deesing (2008) state that temperament and behaviour as well as physical appearance "will be unique to different breeds of the same species of grazing animals" (p. 16), and in this way genetics combined with the livestock's life experiences have an important impact on how livestock react to handling.

Periodically, the ranch offers courses of animal welfare to their employees and managers and cowboys of other ranches in the area. The recurrent offering of courses in different settings and among different participants works as a reinforcement for dialogical teaching and learning processes. Commonly, participants of the course, especially the cowboys, do not interact amongst themselves frequently either inside or outside of the course settings and instead interact more with the trainers. However, this recurrent reinforcement is used as an opportunity to encourage and mobilize dialogue among all course participants, cowboy to cowboy and cowboy to manager, enhancing social tensions inherent within society.

The number of individuals per rational management course offered by the team of trainers usually ranges from 25 to 30 people. The cowboy and the manager interviewed observed that an ideal number of participants for the course to progress effectively could not surpass 25 people. A larger number of individuals could negatively affect the activities that are performed in practical classes, where all participants of the course would not have enough time to perform the exercises with the animals assigned by the trainers. Actually, a group of 25 is considered a big number as it is, inhibiting the shared learning the trainers and participants can accomplish with one another in an individual basis. With these many people involved trainers are less likely to have the opportunity to be fully exposed to the context of each specific ranch and create sustainable knowledge and technologies alongside the acting subjects of each ranch. To enable a more effective dialogical communication in a rural extension course, the trainers prefer a smaller group of participating subjects whom they can near their meanings and senses to in the teaching-learning processes.

The content of the rational management course includes:

- Animal rational welfare management in paddocks of rearing and fattening and corrals;

- Pre-slaughter management;

- Neonatal management. 


\section{Results and discussion}

It is our aim to present the collected data from a dialogical course in rational management and use the theoretical framework proposed by linguist Mikhail Bakhtin on dialogism. In the following pages we introduce the research data separated in sections that best analyze and describe the animal rational management course offered by the team of trainers to the manager and cowboy of a rural Brazilian ranch.

\section{Accounts on course structure and expectations}

The first interview we conducted for this research involved the three members of the team of trainers. We sought to study the structure of the courses offered in the Brazilian beef cattle ranch and understand the nature and development of the relationships in the teaching-learning processes.

For the trainers, the most efficient way to construct productive environments based on rational animal management is through a long-term consulting and training basis. The ideal time frame of this type of service is of at least a year of work, preferably on the site. Trainers find this type of activity is more comprehensive because it composes a whole cycle of teaching and learning with a duration period long enough for an acquaintanceship to develop between trainers and the cowboy and manager involved in the training. According to Bakhtin's theory, a longer time of acquaintanceship between people tends to better approximate the subjects' senses and meanings. Bakhtin (2010) proposes that sharing lived experiences allows the creation of similar senses. In Brazil, having similar senses of shared experiences is a necessity as it is a country with such an extensive continental dimension that different words and diverse perspectives, depending on the region of the country, come into play when making sense of a same situation or humanized object.

Moreover, the stark difference in education levels of the cowboys, managers and trainers leads to different employment of words. It has been the case, as observed by the trainers, that the lack of a previous coexistence among the individuals involved in the courses results in misunderstandings related to the dissimilar senses produced. This misunderstanding exacerbates when cowboys become self-conscious and filled with inhibitions when they do not understand the proposed content of the courses. The inability to fully understand some words and concepts employed by the extension agents, during practical and theoretical classes, was observed by the trainers during their administering of the courses. The inhibition is manifested and cowboys tend to remain quiet, especially on the first day of the course and training. However, according to the trainers this is common with cowboys in any given course.

In order to avoid a discrepancy in produced senses and meanings, a previous coexistence between trainers and cowboys becomes necessary when employing dialogical communication. A previous coexistence nears the meanings and senses of the subjects and affects the enunciations made by one subject on those of another. In this way a previous coexistence is a significant teaching-learning process with historically built bonds of trust between the subjects (Clot, 2007). Moreover, as Bakhtin (2010) proposed in his studies, living experiences together allows the sharing of a same horizon of 'meaning'. According to one of the trainers, "in the consulting service we have a better integration [with the course participants] which is maybe due to the opportunity of having met and become better acquainted in the course of time".

However, the trainers interviewed understand that for the majority of these rural properties, a previous and long-term consulting and training service comes at a high financial cost, making this option very restrictive. For this reason, ranches are presented with an alternative; the application of a highly focused dialogical course lasting six days. Although the trainers reported that results can turn out positive in this shorter time frame, results that can come from an annual consulting would more substantially accomplish a more comprehensive mobilization of ranch employees and demonstrate results of Dialogism, specifically the nearing of senses and meanings between course participants.

Course schedule and procedures

The six-day courses offered to the ranches are divided in three stages:

- Stage 1 has a duration of 24 hours during the first three days of the course, in which various types of diagnoses are realized in the ranch;

- Stages 2 and 3 last 12 hours each, and they consist in the conducting of theoretical classes and practical training interspersed with theory during the 4 th, 5 th, and 6 th days of the course.

In the first stage of diagnosis when the trainers arrive at the ranch where the course will be offered, they collect relevant technical and socio-economic data. The trainers first identify what type of management the animals receive at the site, the degree of reactivity of the animals, and the state of the ranch facilities, determining the adequacy of the practices of animal welfare in place. In a following step the trainers point out the present problems and recommend specific, practical and viable solutions for the site. In the socioeconomic diagnosis, the living and working conditions of the cowboys and their families are also assessed.

Trainers claim that in ranches where the living and working conditions of the cowboys and their families are bad, for example if there is a lack of safety in equipment and the quality of food is questionable, the teaching-learning processes will not render positive results. In these case, sometimes the animals may even receive better treatment than the cowboys. In the ranch under study this is not the case. On the contrary, the trainers identified that the ranch provides good employment and 
living conditions for all its employees. Examining and acknowledging social constraints, as represented in the working and living conditions of the employees, will be a determinant in foretelling whether the communication will be problematic or if dialogical communication can be more easily achieved. The better living conditions for cowboys in a given ranch demonstrate less social constraints between employer and employee and are indicative of an inclusive perspective from the owner who sees his employees as key players and recognize the systematic betterment of the ranch as whole.

\section{Engaging in dialogue}

During the diagnosis stage trainers begin dialogue with some cowboys to also find out, even intuitively, the knowledge level the subjects may have about the practices of animal rational management. It is during these dialogues that the trainers begin to sort their senses and meanings and relate them to the words employed by the subjects that live and work in the ranch and its surroundings. They begin to employ words in the courses that are commonly used by cowboys. This includes using common jargon when dealing with the cattle. For example, when explaining how to deal with the cattle when cattle are tired, the trainers will opt using the informal concept of tired animal "animal aguado" or "sloppy animal", or when referring to a bruise found in the cattle the trainers will enunciate the more commonly used term in the ranch "pisadura", a term that more or less translates to the informal "black and blue marking" or "blackening" commonly and informally used in the English language.

It is also at this point that a relationship of trust with the cowboys begins for the trainers, facilitating the exchange of experiences on the topic covered in the course and also about other topics, including their quality of life in the workplace and their houses in the ranch's colony, and the overall quality of life of their families. When the trainers asked about his "quality of life" in the workplace, the cowboy mentioned stress caused by exhaustive work principally arising from physical fatigue when the work is done carelessly and with brutality with the animals. Trainers claim that when course participants are asked about the quality of specific living conditions provided to them, such as food quality, course participants will only fully contemplate these if the conditions are very negative and deficiencies are strong and evident. The trainers reported the cowboy's living conditions was not an issue, and hence, the conditions were positive.

According to Barros (2011), in the Bakhtinian approach the dialogues between subjects participating in a same situation or occurrence are divided into two contexts that place the speakers as responsible for their discourses. One context is verbal and the other is non-verbal. The verbal context presents three components: (1) sense, or a unique and personal understanding of a word, (2) meaning, which is a common concept of a word for a group of people, and (3) emotion, a value observed in the intonation of words, expressed when making value judgments. Enunciations always possess a meaning, a sense, and an emotion. The non-verbal context presents three assumptions: a common space in the real world, a common comprehension and understanding between the two subjects of a determined existing situation, and a common evaluation between the subjects about the existing situation. The non-verbal context is integrated to enunciations constitutively.

Subjects communicate with one another and organize and structure meanings and senses through enunciations, per agreement with the concrete world they relate to. An enunciation is the principal object of sense-making and its understanding presupposes a determined socio-historical context that is common between the subjects engaged in the dialogue. In order to fully comprehend the enunciations made, the trainers and the subjects must live in a similar way and culture, with shared experiences and shared contexts. This means that the socio-historical context must be known in order to understand the enunciations within the content. The understanding of enunciations present in the discourse implies the identification of its formal and normative meaning. Communication necessarily finds itself inserted in the communion between individuals within shared contexts, as language is social and for there to be comprehension of the enunciations between the subjects an existing shared experience is necessary (Kramer, 2007).

Dialogism presents an internal and an external path. The external dialogical path is found in the enunciations of a verbal inter-relationship between two subjects and the internal path refers to the meanings and senses related to the inter-content contained in the enunciations. The inter-content in the enunciations composes the subjectivity of each subject. In an enunciation no word truly pertains to the speakers, as in its wake a word brings singularities and perspectives from an infinite amount of voices within each participating subject. The interpretation of the enunciations of each one of the speakers necessarily involves their values. This is starkly different to the "source" of the diffusionist theory, whose message, with already attached values, is placed at the centre of a given course. In the socio-historical dialogical perspective neither of the speakers are the centre of enunciations, as the location of an enunciation is the space that is created between these subjects (Barros, 2011). In a dialogical course there is no "source" nor is there a "recipient" who receives the message, instead there are two speakers who make enunciations with their personal attached values.

The numerous voices within a didactic context that is not hierarchical but is instead horizontal in nature will necessarily produce a training course with a polyphonic approach (Bakhtin, 2010), where equipotency of voices and enunciations are sought. In a dialogical course a multi-vision about the same content is introduced by the participating subjects. Polyphony presupposes the possibility of significant dialogue between the participants because the subjects' various points of views and value judgments present in their enunciations will be confirmed, guaranteeing a space for equipotent voices where nobody's values or views are superior to anybody else's (Morson \& Emerson, 2008). Furthermore, within this polyphonic context, the subjects will think via thoughts, voices, and consciences (Morson \& Emerson, 2008). Polyphony is highly present in the study and is exemplified through the ideas proposed by the course participants when they pose questions and suggest concepts, and then subtly ask trainers for feedback. The trainers assessed that this newly created dialogue between they and 
course participants reinforces the teaching and learning relationship. The course participants' shared information, insights and even doubts through dialogue adds great value and experience to the content.

In this way, dialogue is merely the starting point of the continuous and not finalized process that constitutes the subjects (Morson \& Emerson, 2008). A polyphonic course does not mean an absence of a guiding path offered by the trainers, but instead it leads to a rotation of exposure and development of the senses made by participating subjects. A polyphonic course necessarily presents a multi-vision of all participating subjects and the multiple and equipotent voices are a requirement for the joint and not finalized construction process of sustainable productive environments.

\section{Dialogue in theoretical and practical classes}

After the diagnosis stage the first day of training begins. A heavy load of theoretical content is conducted in the morning and afternoon, with a lunch break in between. During the training the extension agents constantly instigate the participants by posing questions about the existent practices in the ranch, which come from the trainers' observations in the diagnostic phase. The trainers seek to produce new senses in the course participants. The extension agents use prompters such as videos, pictures and images, as well as physical demonstrations to depict new theoretical content.

In the second day of class a practical activity is conducted in the morning in which trainers seek a stronger dialogue with course participants. It is at this point when the trainers look for critical reflection from the participants about the content learned the day before. The trainers ask the course participants to imagine how the content could be adapted to their present work routines in the ranch. During this exercise, the cowboy and the manager look for a comparison between the productive routine exposed in the course and the one they perform. Comparing these is a critical exercise involving reflection on the cowboy and manager's former professional postures and their respective histories. It is at this more precise moment when the subjects re-make sense of their productive and historical contexts and reflect on the past, as this has the power of revising the present and treading the future (Kramer, 2007). During the course the trainers observed the cowboy's interest in participating in the practical demonstrations in the corral. This is a differentiated stance from the cowboys as it is a more active stance in comparison to their more introspective and reserved stance in the theoretical class.

For the conclusion of the course, on the last day, a new theoretical class is conducted in the morning and the subjects are exposed to the final course content. For this activity the trainers use videos and pictures of rational management practices so that the course participants can draw their own conclusions of the content introduced throughout the course. During the afternoon on the same day, one last practical class is conducted in which the subjects are asked to recreate the type of management learned in the entire course. It is intended to create a dialogue again with the participants so that they reflect upon how this activity can be performed in their own sites of work. We learned that the cowboy under study as well as other cowboys in the course opened up during this stage and voiced their difficulties in recreating the management practices. Cowboys introduced and presented their own ideas on ways they thought the difficulties could be resolved at the corral during the exercise and at the ranch if the same problems were to arise. These ideas came directly from their extensive experience with the cattle at the ranch. The trainers found this to be a revealing learning experience for them as they became introduced to new methods of executing the practices they teach in the class that may prove to be more sustainable in a given specific ranch. The trainers got a glimpse of how the management practices can and will be implemented in the ranch and the cowboys' reasoning and logic behind it.

According to the trainers the act of reflection of all the subjects involved in the course, including themselves, is one of the most important accomplishments of the teaching-learning process throughout the course. Both the cowboys and the trainers benefit from the reflections forged through mutual discovery and learning. Through the trainers' reflections they are able to understand the practical difficulties in a given ranch when implementing the management practices they teach. They near their senses and meanings to the cowboys' and are more likely to showcase the difficulties exposed by the cowboy in their future extension profession activities. The trainers are forced to critically think about the course and assess its content, especially when applied in specific ranch scenarios where external and unique factors inevitably play important roles in the implementation of rational management practices. In this way, the trainers also benefit from some newly introduced knowledge exposed and at times produced during the course. The sharing and creation of knowledge will result in a more sustainable rural extension which is made possible through the horizontal communication brought about by Dialogism, or dialogical communication.

According to Amorin (2012), activities between subjects expressed in the concrete world can be divided in two categories: acts and actions. The act of thinking will always be unique, it is a gesture by which subjects reveal and risk themselves in the concrete world because it is within this active context where they take full responsibility for their thought. In order to truly obtain full knowledge it is necessary that the subjects think critically. During the act of reflection the subjects position themselves in their possible futures, as depicted by the cowboys' more distinguishable active position in the practical portion of the class. The dialogical subject's act of reflection possesses a distinct awareness of what his role can cause in the treatment of animals. The cowboy must actively and responsively recognize his validity in the productive processes to be newly inserted in the ranches. When being co-responsible in the development of new technologies the cowboys, alongside the trainers, leave their own imprint and their understanding on the development of these technologies and practices.

On the other hand, actions are defined as repetitive movements that are automatic and uncritical (Amorin, 2012). When we observe the training courses based on diffusionist theory we witness a vertical and hierarchical posture from rural extension agents as they strive for the adoption and assimilation of course content by the people receiving training or a course. In a diffusionist training cowboys are expected to adopt the scientific content proposed to them by rural extension agents as 
proposed by academia, without assuming any responsibility. The course participants do not necessarily recognize themselves in those contents as those are very different from the ones they have historically constructed. Trainers exposing the content become mere "sources" or messengers of academic content, merely transferring knowledge to course participants. Therefore, in a non-dialogic context all subjects involved are passive subjects, but especially the cowboy in his decision to implement the course material in his productive context. In dialogism the cowboy as well as the other course participants including the trainers will be active and responsible subjects and therefore true agents of change.

\section{Conclusive course observations}

\section{Structure and dialogical process observations of the course}

When asked about the opinion on the structure of the course, the manager found the three-step course is well-structured, meeting the production necessities of the ranch. He would not recommend any changes. However, the cowboy disagreed with the length of the course. For the cowboy the ideal amount of days that should make up the training is five days, in which the preliminary diagnosis stage takes place during the first three days and the theoretical and practical classes the following two days. We believe that the cowboy's preference may be based on his previous experience taking two courses in the past with the same trainers. He may have found the information given on this third occasion repetitive and taking away from his daily routines.

The trainers informed us that generally the course participants are cowboys, managers, ranch owners and other ranch employees. The trainers have observed a posture of significant inhibition from the cowboys in some courses in the past that has resulted in inhibited dialogue. Both the cowboy and the manager believe the dialogue between the subjects would be more substantial if course participants were made up of only the cowboys and other employees, excluding the managers and the owners. The observed course participants' inhibition to begin dialogue amongst themselves may be indicative of the environment of the courses. Having a mixed audience in a rural extension course or training (cowboys, ranch owners and managers of cattle ranches) may not create the most polyphonic environment by the fact that the subjects do not feel they can dialogue horizontally among their peers during their educational practices (Bakhtin, 2012; Zuin, Zuin, \& Manrique, 2011). They do not see their managers and/or ranch owners as their peers, and therefore they cannot see the environment as non-hierarchical. The trainers are conscientious of the barriers in communication. They believe that if these communication barriers were broken down the course would be of more interest and substantial change in the subjects' respective roles at work because the voices and points of views about the treatment of animals would multiply. This multiplication would bring about less inhibition and more horizontal dialogue, as aimed by dialogical communication.

However, while a course structure with different participants of the ranch is not ideal in the sense that it inhibits participants from relating to one another, the course may still very well achieve principal tenets of dialogical communication. An absence of dialogue does not necessarily mean a less dialogical process. In Ponzio's (2010) studies, he argues that when one of the subjects remains quiet during a dialogue the subject can still be inserted into a dialogical context. The author differentiates the word quiet from silence; quiet leads to a dialogical communicative context, while silence is indicative of monologue. In other words, when remaining quiet a subject may still be connected with an enunciation made, allowing a space for comprehension of the topic worked in the enunciations. This comprehension-making generates new senses in the subject, even when the subject has not enunciated his thoughts about the topic. In this way the subject is keeping quiet but is still in contact with the on-going enunciation. On the other hand, silence is only a perception of sound that does not generate new senses between subjects, a silenced subject obtaining information from a course with a diffusionist bias listens without reproducing new senses.

\section{Training process observations}

In another moment of the interviews we sought to understand the senses made about the paths taken during the training process in the beef cattle ranch. According to the trainers, there is much flexibility in the content of their courses. The trainers use the information collected in the diagnosis stage to plan the path the educational practices that will make up the course. As one of the extension agents put it, "during the capacitation [training] process, the [didactic] methodology varies and depends on the targeted audience." After learning about the recurring problems, unique to the ranch under study, in the diagnosis stage, the trainers prepared the cowboy and the manager to address them by providing relevant material within the course content. When asked, the manager and the cowboy stated that one of the most adequate activities in the course is the incorporation of activities presently occurring at the ranch. More interest was evidenced in the participants. According to the trainers, by touching upon these present occurrences the cowboy and the manager felt less worried for leaving their workplace and not working in their daily productive routines at the ranch.

During the theoretical classes the trainers use slide presentations through a multimedia projector containing text, images, pictures, graphs and short clip videos with an average duration of three minutes. When we inquired if these created or instead inhibited the creation of neared senses and meanings between subjects the trainers stated that it depends on the content they wish to work. For example, if the objective of the course is to demonstrate how to care for a newborn calf, the trainers will choose to show a video demonstrating the series of actions that cannot be replicated by the cowboys or managers of the ranch in the course. According to the trainers, some content needs to be presented in short clip video format because pictures could lead to different interpretations and thereby inhibit the approximation of senses and meanings between the trainers and the course participants. For one trainer short clip videos need to be as short as possible to avoid losing the 
cowboy's attention. The trainers prefer to use static images and pictures when they introduce content that may not need a series of actions to take place in a specific order and can be depicted and practiced during the practical sessions of the course. For visualization of small details and to more precisely depict a concept, the trainers agreed that the best method was the use of pictures.

When the manager and cowboy were asked if they agreed with the trainers about the best way to expose the content of the course, they said the slides should present very little to no text and graphs because many cowboys in the course lacked basic literacy skills. The manager suggested that the cowboys prefer videos because they are more dynamic than pictures. However, the cowboy interviewed disagreed with the manager and stated that he preferred pictures. For him, pictures provide more time to pay closer attention to the content. Sometimes some videos may contain a lot of information which results in less available time to create new senses and meanings. The cowboy went further in his analysis stating he prefers theoretical classes because these provide external examples through the different pictures and videos exposed.

Another strategy employed in the courses is video recording of existing practices employed in the ranch by the course participants themselves, specifically of the cowboys in the course. By recording short video clips in the diagnosis stage the trainers then share these with the course participants in the theoretical class to create dialogue and opinions from the cowboys and managers. The trainers aim to mobilize the participants towards reflecting on better practices of animal welfare and rational management. For Souza (2007), when the subjects observe their activities through the recording it is impossible to become immune to the process of giving new significance to their own acts. She argues that the subjects see themselves in the videos and create new behaviours and experiences.

Trainers first showcase an incorrect management practice in the recording. As a trainer put it, "we first exemplify an incorrect management practice which brings the cowboys to perceive and understand that the animals have wills and behaviours of their own." By exemplifying tangible practices all subjects become involved in analyzing and critically debating the traditional management postures and practices observed, necessarily being inserted in the teaching-learning context. The manager and the cowboy interviewed believe this is an optimal didactic path. The cowboy narrated that when he sees himself in the videos during theoretical classes new dialogues are created, that otherwise wouldn't be, between him and the trainer as well as with the other cowboys and managers participating in the course. An exchange of the course participants' historically constructed realities and experiences occurs. A subject's experiences are no longer individual experiences; instead, they have become collective, generating in the group a path of awareness.

The didactic exercise of re-assigning a dialogical meaning by exposing situations through videos is found in the works described by Clot (2007). The activity of crossed auto-confrontation employed during teaching-learning processes encourages discussion between pairs of subjects who are specialists in the work area. The author states in his studies that this type of educational approach is of more significance because the specialists know their productive context. When the course participants verbalize the registered activities in the recordings a real path to mutual understanding of content is possible with others who are not specialists in the same productive context (or cowboys from other ranches), as all subjects are inserted in the same productive context through a video. Their senses and meanings are neared and more in tune with each other's as opposed to other subjects who did not experience the common productive context and shared the same experience. To a great extent, these innovative strategies necessary to jointly develop sustainable practices replace other activities preferred to near the senses and meanings between subjects, such as a long term consulting and training service.

\section{Unique perspective in dialogism}

In dialogism events occurring between the subjects in different cattle ranches will be unique and non-repeatable (Faraco, 2009; Morson \& Emerson, 2008). The educational diffusionist context looks for the universal and not the particular, and for a generalized norm and not an event. Systems are sought in detriment of individual acts. In the dialogical communicative context subjects assume a participating role that is not indifferent to their peers and of the occurrences that permeate their posture in the concrete world. All course participants' value judgments and postures are truly individual and unique. Participants are encouraged to reflect on their attitudes about the unique way they carry out their work in the ranch.

For Bakhtin (2010) and Faraco (2009), during dialogue subjects go further than reflecting, they refract senses and meanings, permeating the interaction between the two speakers in the concrete world. To merely reflect means that words will behave as a reflection in a mirror, where the senses and meanings are the same as the other subject's. This is common in the diffusionist approach, which seeks the formulation of a unique sense and meaning between extension agent and farmers or cowboys which results in a cultural invasion (Freire, 2006). For difussionist trainers their senses must be reflected exactly the same on the senses of the cowboys, managers and owners of the ranches. In dialogue, however, words are refracted within the subjects. Through dialogue senses and meanings about situations are constructed at each unique moment. When words enter the subjects' conscience they will bathe in a sea of their lived experiences. As the words resurface into the concrete world the words have become unique. It would not have been possible for the subjects to have given new senses and meanings without having had the words go through the paths of refraction (Faraco, 2009).

\section{Pedagogical context based on mobilization}

The trainers argue that transformation by way of adopting the practices of animal welfare in the productive reality of the ranch will only occur if all of the subjects involved in this process are mobilized. In the studies of Charlot (2005) he highlights the difference that occurs in pedagogical contexts that stride for didactic activities that are mobilizing, as opposed to motivating. For the author, motivating activities possess an outside looking in bias of the educators (or the trainers), making 
the activities temporarily important for the subjects receiving the courses. However, in a dialogical course the subjects are mobilized, as activities are proposed from the inside looking out. Mobilization aims to achieve critical development in the subjects from the productive contexts. The subjects receiving the course must become conscious of activities conducted within their own realities. Mobilization results in course content being more durable and significant for all subjects involved in the course.

The trainers observed that the mobilization of the cowboys and the owners of the ranches occur in a less traumatic way when they observe gradual improvements in the ranch's productive routines. Improvements that are gradual, slow and almost imperceptible to the eye occur along a historical process. In the dialogical perspective new acts from the subjects are expressed by innovations (Morson \& Emerson, 2008). As opposed to radical innovations irrespective of a specific ranch's particularities as well as one-size-fit-all technologies that make up the content of non-dialogical diffusionist courses, dialogical courses enable innumerous and miniscule changes within the productive processes and routines of the ranches that occur as a result of the subjects' acts. Innovation in the dialogical context takes into account the innumerous voices of all the subjects that will employ the new technologies and practices and the innumerous and miniscule changes that they introduce and implement in the cattle ranches. The act of innovation is linked to responsibility as well as to the creativity of the subjects. The subjects' creativity will be authenticated in the transformation towards a more sustainable productive reality in the ranch as it becomes inserted in all the involved subjects' continuous, historic, and active processes of animal treatment and handling.

The trainers believe the cowboy of this ranch is more open to creating new knowledge on animal welfare. As for the mobilization of the manager, trainers reported the manager under study did not accept changes to animal management as proposed in the course with ease. Trainers believe the main concern for the ranch managers is the belief that trainers may be there to take the managers' managerial jobs. In reality, the trainers offer their courses as asked by the property owners who seek to transition towards a more sustainable productive and economical viable rural property. At other times, the managers believe this new way of working will take longer and will be less productive. Even when financial benefits are obvious for the subjects inserted in the productive context, they are found to be more willing to purchase new technologies than they are to adopt and invest in efficient welfare management practices (Grandin, 2003).

\section{Life quality observations}

In the final part of the interview we asked the subjects what the results were in the productive processes of the ranch after the completion of the course and what these results represent in the quality of life of the cowboys and their families. The trainers asserted that they observed some improvement in the quality of life of the cowboys in the workplace, as well as better relationships among the ranch stakeholders. The cowboys specifically mentioned a decrease in stress and accidents in the workplace due to better management practices employed with the animals; an obvious improvement in personal and work relationships between cowboys, managers, owners and rest of the employees in the ranch, and; an improvement in the relationships between the cowboys and their families. Similarly in studies conducted by Quintiliano and Paranhos Da Costa (2008) in other Brazilian rural cattle ranches, an improvement is also confirmed in the quality of life of employees after animal welfare activities began to be part of their productive routines. Furthermore, trainers no longer use the term "animal welfare" in their courses. Instead, they use "welfare of the ranch" as a whole, looking for an improvement in the quality of life of the cowboys before the animals.

\section{Thoughts on progress and success}

A positive aspect affecting the progress of the course relates to the historically constructed experience of the cowboys in the course. The trainers observed that the cowboys with more experience in the field tend to learn faster and act more responsively. Extension workers observed that the younger and less experienced cowboys tend to neglect practices of animal welfare exposed in the course during the diagnosis stage. The cowboy interviewed for this study is an older and more experienced cowboy.

The team of trainers reported that the courses are made available only for ranches in which the owners and other stakeholders have observed a need for the adoption of animal welfare practices in their productive routines. The trainers believe the clients need to recognize a need in the adoption of animal rational management practices, sometimes by preference and other times by necessity, before being influenced to modify their management. Farms, ranches and slaughterhouses that require some type of certification following market demands are the majority of the clients requesting these types of courses in Brazil. Market demands that call for improving handling of livestock have been in part brought about by international standards and animal welfare auditing programs by major meat-buying customers (Grandin, 2007).

Finally, the trainers concluded that there is no use of a good course with cowboys and managers if no continuity of animal welfare practices is given in the day to day activities. This continuity can be made possible with appropriate monitoring by extension agents. The necessary monitoring can be accomplished through the offering of new courses seeking to strengthen the already worked theme in animal welfare or courses with new content that is of interest and need for the cowboy, manager, and other subjects involved in the first course. To an extent this has been accomplished with the cowboy under study, as he received two previous courses by the extension agents prior to this rational management course. Providing 
continuity will further near the senses and meanings between the subjects, extension agents and the ranch stakeholders, allowing for the foundations of dialogism and creation of long-lasting horizontal relationships.

\section{Conclusion}

In order to create and maintain a high standard of animal welfare, training employees in better management practices is as, if not more, important as using innovative technologies and well-designed equipment (Grandin, 2006). The owner of the ranch in this case study understood how important continued education in animal welfare and rational management was for his ranch. He realized the resulting economic and social impacts as the demand for more sustainable beef products is on the rise in Brazil.

We studied the dialogical extension approach used in one of the courses available to two employees of the ranch, a cowboy and the ranch manager. This extension approach, dialogism or dialogical communication, departed from the traditional diffusionist approach used predominantly in rural Brazilian territories. To expose the methodological content used in the extension approach based on dialogism in an animal management training course, we used the reference framework of linguist Mikhail Bakhtin. We argue that through the variety of voices of multiple subjects present in the course and the resulting interconnections of their enunciations a new technology or practice is jointly developed and can subsequently be more sustainably inserted in the productive routines of the Brazilian beef cattle ranch.

In dialogical training courses, subjects are responsible for the unique and singular events occurring in their ranches. These subjects do not have to present an alibi for their choices and existence. Even when sharing the same context with the trainers and other course participants, including the manager, who possesses a higher level of academic knowledge, cowboys in a dialogical course are encouraged to develop their unique and different value judgments. These value judgments are constituted by the materialization of their acts when implementing better management practices in the ranch.

In dialogism every person is constituted by their infinite number of relationships with other subjects and no subject in its relationship with others is ever separated from the processes of communication. In this way, the main objective of dialogical communication is for extension agents to near their senses and meanings to those of the participants', avoiding occurrences of cultural invasion. Extension agents are able to identify the course participants' senses and meanings with the enunciations they employ once dialogue is initiated in the different stages of the training. It is through enunciations that subjects communicate with one another, and organize and structure shared meanings and senses. Moreover, dialogism guarantees a space of equipotent voices where a non-hierarchical relationship of equals can be co-created. The equipotency of voices is a prerequisite for the joint construction of sustainable productive, economically viable and socially just environments in rural territories.

Equipotency and polyphony are viable when environments are highly participative. Providing these environments has not been the norm in Brazilian rural extension because of the social constraints inherent in that society. Social constraints are more obviously manifested through the inability to create a dynamic and equal "peer to peer" horizontal communication between university educated trainers, ranch or farm owners and managers and less educated cowboys and farmers. In dialogism, the social relationships are necessarily driven by dialogues (verbal context) and non-verbal contexts that require trust and a previous extensive coexistence between the subjects. By promoting dialogue during theoretical and practical classes through a variety of strategies, the trainers mobilized course participants to create and re-assign senses and meanings. Inversely, trainers learned from the reassigned senses and meanings of the cowboys. As all the subjects become successfully mobilized, the dialogical course on welfare management has become a two-way learning environment.

The principal objective of the people involved in the production of Brazilian livestock is developing rural productive environments that are economically viable, environmentally sustainable and socially just. To think of livestock production with this productive profile requires a dialogical posture that enables a joint creation and development of practices and technologies between all the acting agents involved in the productive agricultural-food chain. The joint development and application of new technologies and practices implies a constant generation of new senses and meanings of all subjects involved. This case study demonstrates the successful development of productive practices in rational management and animal welfare constructed by all the subjects involved in a welfare management course, which as a result also improved their social relationships within the workplace and the quality of life of the cowboys and their families.

\section{References}

Amorin, M. (2012). Para uma filosofia do ato: válido e inserido no contexto. In B. Brait (Ed.), Bakhtin: dialogismo e polifonia (pp. 17-43). São Paulo: Editora Contexto.

Bakhtin, M. (2010). Marxismo e filosofia da linguagem (14th ed.). São Paulo: Ed. Hucitec.

Bakhtin, M. (2012). Problemas da poética de Dostoiévski (5th ed.). Rio de Janeiro: Forense Universitária.

Barros, D. L. P. (2011). Dialogismo, Polifonia e Enunciação. In D. L. P. Barros, \& J. L. Fiorin (Eds.), Dialogismo, Polifonia, Intertextualidade; entorno de Bakhtin (pp. 1-9). São Paulo: EdUSP.

Bonamigo, A., Bonamigo, C. B. S. S., \& Molento, C. F. M. (2012). Boiler meat characteristics relevant to the consumer: focus on animal welfare. Revista Brasileira de Zootecnia, 41(4), 1044-1050.

Charlot, B. (2005). Relação com o Saber: formação de professores e globalização: questões para uma educação hoje. Porto Alegre: Artmed.

Clot, Y. (2007). A função psicológica do trabalho (2nd ed.). Petrópolis: Editoras Vozes.

Ducrot, O. (1987). O dizer e o dito. Campinas: Pontes.

Faraco, C. A. (2009). Linguagem E diálogo: as ideias linguísticas do circulo de Bakhtin. São Paulo: Parábola Editorial.

Freire, P. (2006). Extensão ou Comunicação? (8th ed.). Petrópolis: Paz e Terra. 
Freitas, M. T. S. (2012). A abordagem sócio histórica como orientadora da pesquisa qualitativa. Cadernos de Pesquisa, 116, 21 -39.

Grandin, T. (1994). Euthanasia and slaughter of livestock. Journal of the American Veterinary Medical Association, 204, 1354-1360.

Grandin, T. (2003). Transferring results of behavioral research to industry to improve animal welfare on the farm, ranch and the slaughter plant. Applied Animal Behaviour Science, 81(3), 215-228.

Grandin, T. (2006). Progress and challenges in animal handling and slaughter in the U.S. Applied Animal Behavior Science, 100(1-2), 129-139.

Grandin, T. (2007). Introduction: Effect of customer requirements, international standards, and marketing structure on the handling and transport of livestock and poultry. In CAB International (Ed.), Livestock handling and transport (3rd ed., pp. 1-19). Wallingford, UK: CABI Publishing.

Grandin, T., \& Deesing, M. (2008). Humane livestock handling: Understanding livestock behavior and building facilities for healthier animals. North Adams, MA: Storey Publishing.

Hernandes, J. F. M., Rubin, L. S., Dill, M. D., Oliveira, S. M., \& Silva, T. N. (2010). Animal welfare in the cattle production chain: From farm to slaughterhouse. In 48 Congresso da Sociedade Brasileira de Economia (SOBER). Campo Grande, Brazil: Administração e Sociologia Rural.

Kramer, S. (2007). Entrevistas coletivas: uma abordagem para lidar com a diversidade, hierarquia e poder na pesquisa em ciências humanas. In M. T. Freitas, S. J. Souza, \& S. Kramer (Eds.), Ciências Humanas e Pesquisa: Leituras de Mikhail Bakhtin (2nd. ed., pp. 57-76). São Paulo: Cortez Editora.

Machado, M. D., Paulillo, L. F., \& Lambert, A. (2008). Fair Trade: The case of orange juice commercialization between Brazil and France. Organizações Rurais E'Agroindustriais, 10(3), 387-404.

Morson, G. S., \& Emerson, C. (2008). Mikhail Bakhtin: criação de uma prosaística. São Paulo: EdUSP.

Ponzio, A. (2010). Procurando uma palavra outra. São Carlos: Pedro \& João Editores.

Quintiliano, M. H., \& Paranhos Da Costa, M. J. R. (2008, October). The application of driving and stunning techniques in South America - Practical experiences of good handling practices in Brazilian slaughterhouses. In Proceedings of the conference on animal welfare at slaughterhouses and killing for disease control, emerging issues and good examples Hindasgarden, Sweden.

Souza, A. J. (2007). Dialogismo e alteridade na utilização da imagem técnica em pesquisa acadêmica: questões éticas e metodológicas. In M. T. Freitas, S. Jobim, \& S. S. Kramer (Eds.), Ciências humanas e pesquisa: leituras de Mikhail Bakhtin (2nd ed., pp. 77-94). São Paulo: Corte Editora.

Zuin, L. F. S., Zuin, P. B., \& Manrique, M. A. D. (2011). A comunicação dialógica como fator determinante para os processos de ensino-aprendizagem que ocorrem na capacitação rural: um estudo de caso em um órgão público de extensão localizado no interior do Estado de São Paulo. Ciência Rural, 42, 1-6.

Zuin, L. F. S., \& Zuin, P. B. (2008). Produção de Alimentos Tradicionais - Extensão Rural. Aparecida: Ideias \& Letras. 